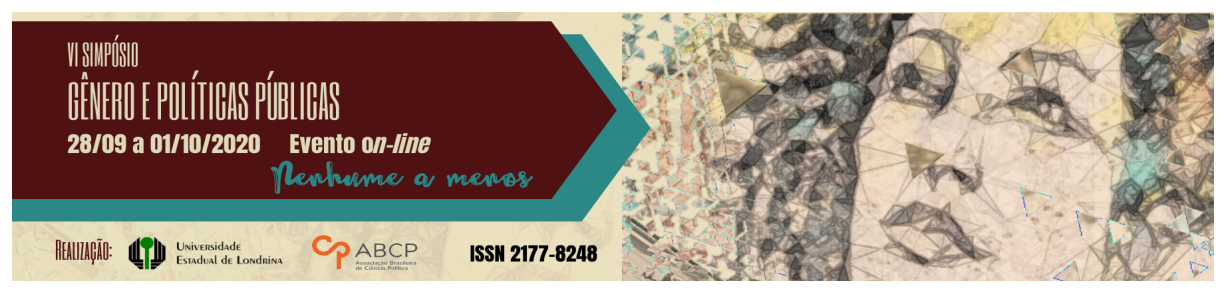

\title{
A participação feminina na Comissão de Direitos Humanos e Minorias da Câmara dos Deputados
}

\author{
Ana Paula Thomaz Pina ${ }^{1}$
}

\section{Resumo}

A presença de religiosos na política brasileira veio se acentuando desde o processo da constituinte, representados pela Bancada Evangélica no Congresso Nacional. O ativismo evangélico ganhou holofotes com os acontecimentos ocorridos na Comissão de Direitos Humanos e Minorias da Câmara dos Deputados, em 2013, a qual elegeu o Dep. Pastor Marco Feliciano (PSC) presidente, propiciando uma forte onda de protestos e apoios a sua liderança nessa comissão. Neste período, aconteceram duas importantes audiências públicas na $\mathrm{CDHM}^{2}$ que provocaram embates entre forças conservadoras e feministas: a audiência pública para "Discutir o aborto"; e a audiência pública sobre a "Violação dos direitos humanos do nascituro". Essa pesquisa tem como objetivo analisar quem são e qual o perfil dos atores e atrizes sociais que participaram desses eventos públicos que tocam diretamente temas afeito ao corpo das mulheres, analisando essas presenças e o conteúdo de suas falas.

Palavras-chave: participação; evangélicos; feminismo.

\section{Female participation in the Human Rights and Minorities Commission of the Chamber of Deputies}

\begin{abstract}
The religion's presencein Brazilian's politics has been accentuated since their constituent has been created. Represented by the Evangelical Bench in the
\end{abstract}

\footnotetext{
1Universidade Estadual de Maringá; mestranda em Ciências Sociais; anaaptp@hotmail.com.

2 CDHM: Comissão de direitos humanos e minorias
}

GT 10 - Gênero e religiosidades 
National Congress. Evangelical's activism became more prominent with the events that took place in the Human Rights and Minorities Commission in the Deputies' chamber in 2013, when Dep. Pastor Marco Feliciano was elected president, providing a strong wave of protests and support for his leadership in this commission. During this period, two important public events took place at the CDHM that between two important groups, conservative and feminist: the public court hearing to "Discuss abortion"; and the public court hearing about "Violation of the human rights of the unborn child". This research 's a is to analyze who are those people and what are their roles as actors and actress who participate in those public events that go straight to the themes related to the women's body, analyzing more details about those presences and the content of their speeches.

Keywords: participation; evangelicals; feminism.

\section{Introdução}

No ano de 2013, o relacionamento entre sociedade civil e sociedade política atinge seu auge em todas as esferas da sociedade, ano marcado por chuvas de protestos nas ruas, assim como grandes repercussões no Congresso Nacional. Neste momento notamos o ativismo evangélico entrando em cena na política nacional, e, na institucionalidade este ativismo tem sido representado pela Frente Parlamentar Evangélica, mais conhecida como Bancada Evangélica, a qual surge na câmara dos deputados no momento da elaboração da nova constituinte. No que diz respeito ao ativismo evangélico, a figura do Deputado Pastor Marco Feliciano marca o embate das discussões políticas em dentro dos assuntos morais e religiosos. No que se refere a representação política, a figura do Pastor Marco Feliciano passa a estar dividida entre dois extremos: "Feliciano me representa" $X$ "Feliciano não me representa". Estes dois extremos evidenciam "múltiplas possibilidades de relacionamento entre instituições do Estado, partidos políticos, e movimentos sociais" (ROMÃO, 2010).

Neste período, aconteceram duas importantes audiências públicas na CDHM que provocaram embates entre forças conservadoras e feministas: a audiência pública ocorrida em 
04/12/2013 para "Discutir o aborto"; e a audiência pública sobre a "Violação dos direitos humanos do nascituro", ocorrida em 10/01/2013.

Sendo assim, 2013, é um ano que vale analisar quem são e qual o perfil dos atores e atrizes sociais que participaram desses eventos públicos que tocam diretamente temas afeito ao corpo das mulheres. $\mathrm{Ou}$ seja, esse estudo identifica e analisa quem participou, com direito à fala, das duas audiências da $\mathrm{CDMH}$, subsidiando a tomada de decisão que diz respeito aos direitos da mulher. As fontes são informações disponíveis no relatório de atividades da CDHM de 2013. São arquivos públicos e fontes primárias dos fatos (CELARD, 2008). Além disso, houveram as notícias que cobriram os conflitos afeitos às audiências, efervescendo ainda mais ativismo feminista e o ativismo religioso na sociedade civil, os quais propiciaram um embate entre essas forças. E por fim, as mulheres realmente participam da formulação de políticas públicas que dizem respeito aos seus corpos?

\section{Os evangélicos na comissão de direitos humanos e minorias}

A discussão a respeito da presença dos evangélicos na esfera pública vem sendo efervescida desde a elaboração da nova constituição, o que de acordo com um dos pioneiros no estudo a respeito da relação entre evangélicos e política no Brasil, o historiador e antropólogo Paul Freston (1993), que sua principal obra tratou do assunto desde a constituinte até o impeachment de Collor, afirma que:

Falar de protestantes e política hoje é falar de quase todos os temas centrais da história brasileira recente: a restauração do Estado de Direito; a Constituinte, a eleição presidencial de 1989; a corrupção; o poder da mídia; a infiltração do narcotráfico; a censura, e temas comportamentais como aborto e homossexualismo (FRESTON, 1993, p.01).

Com o momento aberto para a elaboração da nova Constituição, em meados de 1980, os evangélicos passaram a participar mais ativamente da política, apoiando a candidatura de religiosos, alegando 
a necessidade de serem representados por parlamentares que defendam sua liberdade religiosa, os interesses de suas igrejas e as doutrinas bíblicas (MARIANO, 2012). Assim, surgiu a Bancada Evangélica na constituinte.

Esse discurso, sucessivamente, surte grandes efeitos e, com o crescimento explosivo dos evangélicos nas últimas décadas, consequentemente, hoje a Frente Parlamentar Evangélica (FPE), popularmente conhecida como Bancada Evangélica, é uma das frentes mais numerosas do Congresso Nacional. A FPE constitui um grupo de parlamentares de diversos partidos ${ }^{3}$ que, em sua maioria, desejam recuperar alguns ideais moralistas e que se autodenominam conservadores. Em pouquíssimos casos há deputados desse grupo em partidos com perfis progressistas, mas estes não entram em evidencia por não estarem de acordo com os interesses da bancada. Os deputados da bancada evangélica são ligados a diferentes igrejas protestantes, sendo elas de seguimentos tradicionais, pentecostais e neopentecostais, predominando os pentecostais ${ }^{4}$ e neopentecostais ${ }^{5}$, cuja maioria são integrantes da Assembleia de Deus e, em segundo lugar, da Igreja Universal do Reino de Deus (PINHEIRO, 2017). Além da presença dos evangélicos, a bancada também é composta por deputados ligados à Igreja Católica que contaram com o apoio de Igrejas Evangélicas em suas respectivas eleições. Atualmente, e de acordo com a atualização do site da Câmara dos Deputados de 2019, a FPE conta com 195 deputados e 8 senadores, tendo como coordenador o deputado Silas Câmara (PRB

\footnotetext{
3 São estes partidos: PL, PP, PT, DEM, PATRIOTA, PSL, PDT, PSD, PRB, PL, PODE, PSC, SOLIDARIEDADE, PROS, PSB, PSDB, CIDADANIA, MDB, PTB, AVANTE, NOVO e PMN.

4 "Pentecostalismo" propriamente é a nomenclatura dada à doutrina de determinados grupos religiosos cristãos originários no seio do protestantismo, fundamentado na crença do "poder do Espírito Santo"(terceira pessoa da trindade cristã) na vida do "crente", após o "batismo com o Espírito Santo", evidenciado pelo "dom de línguas" ou "língua estranha", esta, a tradução mais comum do termo grego glossolalia. No Brasil a doutrina foi fundada em 1911.

5 Vertente evangélica que cresce no Brasil a partir da década de 1950, baseada na doutrina do pentecostalismo, mas que também tem sua doutrina baseada na teologia da prosperidade.
} 
- AM), constituindo uma das maiores frentes parlamentares no Congresso Nacional.

Trataremos no decorrer desta pesquisa com uma análise documental sobre a presença de evangélicos na Comissão de Direitos Humanos e Minorias da Câmara dos Deputados em 2013, e a sua influência a respeito da tomada de decisões referente ao corpo das mulheres, sendo estes evangélicos pertencentes a política institucional ou a sociedade civil, tendo em vista que os deputados da bancada evangélica, vão ganhando força devido suas bases presentes na sociedade civil. Aqui, trataremos de 2013, pois neste momento, ativismo evangélico entra em foco a partir dos acontecimentos políticos ocorridos na Comissão de Direitos Humanos e Minorias da Câmara dos Deputados, protagonizado pelo Deputado Pastor Marco Feliciano, eleito presidente da mesma. Neste período, fica armado um cenário de interação entre determinados atores da institucionalidade e atores da sociedade civil, utilizando-se de suas respectivas bandeiras, para defender ou para se opor à atuação de Feliciano nesta Comissão. Esta interação entre estado e sociedade fica registrada em documentos, sendo eles, documentos governamentais, e também, documentos de grande circulação nacional.

Todo este aumento progressivo de deputados evangélicos eleitos na Câmara, entre outros, movimentaram muito o debate acerca da relação entre política e religião. Portanto há um período muito importante para a história do ativismo evangélico no Brasil. O momento em que o Deputado Marco Feliciano do PSC-SP, pastor da Catedral do Avivamento, uma igreja neopentecostal ligada a Assembleia de Deus, e uma das figuras mais conhecidas da Bancada evangélica, é eleito como presidente da Comissão de Direitos Humanos e Minorias da Câmara (CDHM), os atores sociais que tratarei aqui ganham a cena. Dois grandes extremos protagonizam o cenário político, os prós e os contra Feliciano. Consequentemente, houve uma forte exposição midiática, portanto, a marca do embate político da contemporaneidade se dá a partir de 2013. De acordo com o artigo de Rafael Bruno Gonçalves, 
As consequências geradas saíram da esfera legislativa federal e adentraram em outros campos. Por exemplo, por meio da divulgação de manifestos de organizações, intervenções de ativistas que atuam na defesa dos direitos humanos, comunidades religiosas, movimentos sociais, e outros agrupamentos que representavam a sociedade civil organizada (GONÇALVES, p 207, 2017).

O deputado pastor Marco Feliciano foi eleito pela primeira vez em 2010, ano em que o número de representantes evangélicos mais aumentou na câmara dos deputados. Ainda sobre a atuação do parlamentar na $54^{\mathrm{a}}$ legislatura e sua eleição para presidente CDHM, eleição marcada por forte comoção na sociedade civil, CASSOTTA (2016), acrescenta algumas ações de Feliciano no congresso nacional:

Ainda no ano de 2013, na Comissão, Feliciano conseguiu aprovar o fim da Resolução que obriga os cartórios a realizarem casamento entre pessoas do mesmo sexo. Também foi contra o projeto que prevê ao parceiro homossexual a condição de dependente do INSS. Foi a favor do projeto apelidado de "cura gay", apresentado pelo deputado federal João Campos, do PSDB-GO, sobre tratamento psicológico para pessoas que se declarem homossexuais. Além disso, criou polêmica em suas redes sociais como Twitter e blogs ao atacar a comunidade LGBT, ser favorável à censura e à redução da maioridade penal. Apesar do seu empenho na Comissão em levar uma pauta "anti-gay", considerada uma vitória pelo segmento evangélico, não houve grandes avanços dessas pautas fora da Comissão. Muitos evangélicos foram contra as declarações do Marco Feliciano, colocando em dúvida a existência de um grupo religioso coeso (CASSOTTA, 2016, p. 84).

A presença dos representantes evangélicos no legislativo tem crescido desde os ano 1980, mas se intensificou mais tarde com "as alianças que deram sustentação aos governos recentes é um aspecto fundamental na dialética de avanços e retrocessos em que se intensificaram as reações conservadoras a reação conservadora." 
(BIROLI, 2018). Uma dessas alianças citadas por Biroli, é a chegada do deputado pastor Marco Feliciano a Comissão de Direitos Humanos e Minorias da Câmara:

Aferradas a visões convencionais de família em sua atuação política (apud, Machado, 2017) e eficazes na ampliação de sua influência político-eleitoral, essas igrejas são importantes atores na renegociação das fronteiras entre o Estado, a política e a religião no Brasil (apud, Giumbelli, 2008). A chegada de um pastor identificado com a ofensiva contra os direitos sexuais à Presidência da Comissão de Direitos Humanos, em março de 2013, expunha essas duas dinâmicas e pode ser utilizada como exemplo de um ativismo conservador de novo tipo, hoje bastante visível na política brasileira (BIROLI, 2018, p. 88).

Sendo assim, qual a influência das decisões destes congressistas conservadores no que diz respeito ao corpo feminino, aos direitos da mulher e a questão do aborto? As mulheres realmente participam da formulação de políticas públicas que dizem respeito aos seus corpos?

Comissão de direitos humanos e minorias da câmara dos deputados 2013

PRESIDENTE: DEPUTADO PASTOR MARCO FELICIANO (PSC/SP)

$1^{\text {a }}$ VICE-PRESIDENTE: DEPUTADA ANTÔNIA LÚCIA (PSC/AC)

$2^{\mathrm{a}}$ VICE- PRESIDENTE: DEPUTADA LILIAM SÁ (PROS/RJ)

$3^{\circ}$ VICE-PRESIDENTE: DEPUTADO ANDERSON FERREIRA (PR/PE) 


\section{Titulares}

\begin{tabular}{|l|l|}
\hline Pedro Guerra (PSD/PR)* & Keiko Ota (PSB-SP)* \\
\hline Pastor Eurico (PSB-PE) & Enio Bassi (PDT-RS)* \\
\hline Henrique Afonso (PV-AC) & Simplício Araújo (SD-MA)* \\
\hline Otoniel Lima (PRB-SP) & Dr. Carlos Alberto (PMN-RJ)* \\
\hline
\end{tabular}

\section{Suplentes}

\begin{tabular}{|l|l|}
\hline João Campos (PSD-GO) & Roberto de Lucena (PV-SP) \\
\hline Walter Tosta (PSD-MG) & Dr. Grilo (SD-MG) \\
\hline Jair Bolsonaro (PP-RJ & Costa Ferreira (PSC-MA)* \\
\hline Severino Ninho (PSB-PE)* & Takayama (PSC-PR) \\
\hline Marcos Rogério (PDT-RO)* & Zequinha Marinho (PSC-PA) \\
\hline Arnaldo Jordy (PPS-PA)* & Lourival Mendes (PTdoB-MA) \\
\hline
\end{tabular}

*deputados não integrantes da bancada evangélica em 2013

A participação feminina na Comissão de Direitos Humanos e Minorias poderá justificar-se mais adiante na análise das duas Audiências Públicas, cujo aqui darei maior destaque aquelas que tratam de pautas conservadoras defendidas pelos ativistas evangélicos, pois nestes eventos acontecem o trânsito nessas fronteiras e a participação da sociedade civil dentro da esfera do Estado com o discurso que culmina para a construção de um projeto conservador, dando ênfase ao assunto a respeito dos direitos da mulher sobre o próprio corpo.

\section{As audiências públicas}

No relatório anual das atividades acontecidas na CDHM da Câmara dos Deputados estão registradas as 23 audiências públicas que aconteceram em 2013. Cabe nesta abordagem, ressaltar as audiências públicas, pois são estas, reuniões públicas onde alguns membros da 
sociedade civil penetram a sociedade política, tendo o poder de exercer na institucionalidade a participação e a ação política. Conforme CÉSAR, 2011, a audiência pública;

é um instrumento colocado à disposição dos órgãos públicos para, dentro de sua área de atuação, promover um diálogo com os atores sociais, com o escopo de buscar alternativas para a solução de problemas que contenham interesse público relevante [...] Nesse evento, também podem ser apresentadas propostas e críticas (CÉSAR, 2011, p. 359).

De acordo com o Relatório Anual de atividades da Comissão de Direitos Humanos e Minorias da Câmara, disponível no site da Câmara dos Deputados, em 2013, como já visto, a participação de evangélicos que compõem a sociedade civil, foi marcante na Comissão, porém, de todas essas audiências públicas, por enquanto destaco justamente as audiências que aconteceram na CDHM, pois estas mostraram a força desse embate entre forças evangélicas conservadoras e as forças contrárias a presença de Feliciano na comissão. $\mathrm{O}$ olhar para essas audiências tem como objetivo analisar quem são e qual o perfil desses atores sociais que participaram desses eventos, os quais na maioria das vezes, dizem respeito as decisões conservadoras sobre a sociedade. $\mathrm{Ou}$ seja, esse estudo identifica e analisa quem participou, com direito à fala, daquelas audiências da $\mathrm{CDMH}$, subsidiando a tomada de decisão que diz respeito diretamente aos rumos da democracia.

Nos estudos a respeito das fronteiras entre estado e sociedade civil, de acordo com ABERS e BULOW 2011, os atores sociais, pertencentes a movimentos sociais;

muitas vezes se mobilizam em prol de mudanças nos processos de tomada de decisão estatal, demandando a inclusão da sociedade civil em novos espaços participativos. Essa demanda implica não somente na criação de espaços de diálogo entre atores da sociedade civil e do governo, mas da maior presença 
de ativistas de movimentos sociais dentro do próprio Estado (Ibid, p. 65).

De acordo com DAGNINO, OLVERA e PANFICHI (2006), “o debate sobre o papel da sociedade civil na construção da democracia deve ser visto como uma luta simbólica sobre o lugar, os atores e a agenda da disputa entre projetos políticos distintos (p.22)", sendo assim estas informações, apresentadas pelos documentos arquivados e os estudos a respeito dos vínculos entre sociedade civil e política institucional, fica evidente a importância das audiências públicas para que haja a conexão entre a sociedade política e a sociedade civil, pois através da análise das audiências que cumprimos a tarefa central nessa questão, que é "estabelecer claramente os tipos de atores civis que analisamos, os espaços públicos em que se movem e os projetos que defendem" (Dagnino, Olvera e Panfichi. p. 23, 2006)

De acordo com o regimento interno da Câmara dos Deputados, para a execução de audiências públicas, todas as comissões permanentes estão sujeitas a determinadas normas regimentais, as quais destaco aqui as que têm relevância para essa análise:

TÍTULO VIII

\section{DA PARTICIPAÇÃO DA SOCIEDADE CIVIL}

CAPÍTULO III

\section{DA AUDIÊNCIA PÚBLICA}

Art. 255. Cada Comissão poderá realizar reunião de audiência pública com entidade da sociedade civil para instruir matéria legislativa em trâmite, bem como para tratar de assuntos de interesse público relevante, atinentes à sua área de atuação, mediante proposta de qualquer membro ou a pedido de entidade interessada.

Art. 256. Aprovada a reunião de audiência pública, a Comissão selecionará, para serem ouvidas, as autoridades, as pessoas interessadas e os especialistas ligados às entidades participantes, cabendo ao Presidente da Comissão expedir os convites. 
$\S 1^{\circ} \mathrm{Na}$ hipótese de haver defensores e opositores relativamente à matéria objeto de exame, a Comissão procederá de forma que possibilite a audiência das diversas correntes de opinião.

Levando em conta o funcionamento das audiências, fica evidente e vale ressaltar, que a participação dos membros da sociedade civil nestes eventos só acontecem a convite do presidente da comissão, nesse caso, o presidente é um pastor, autointitulado conservador e membro da bancada evangélica, assim como quase todos os membros da comissão. Tendo isto como base, a seguir analisaremos as audiências públicas que aconteceram na gestão do pastor Marco Feliciano e que tocam diretamente os assuntos referente ao corpo da mulher.

\section{A participação feminina nas audiências públicas}

Audiência pública sobre a violação dos direitos do nascituro

Audiência Pública Realizada em 10/07/2013: A Violação dos direitos humanos do nascituro foi tema de Audiência Pública em atendimento ao Requerimento $n^{0} 45 / 2013$, do Deputado Henrique Afonso. Foram tratados assuntos referentes à proteção de mulheres vítimas de exploração sexual e aspectos constitucionais e jurídicos que tratam da proteção de direitos humanos, especialmente do nascituro, que é protegido pela Constituição Federal. A importância da defesa da vida e da família foi ressaltada (RELATÓRIO ANUAL CDHM, 2013).

Esta é outra audiência que contou com a participação de líderes religiosos, como o Padre Paulo Ricardo de Azevedo Júnior, professor e mestre em Direito, e o Deputado João Campos, autor do requerimento de instalação da CPI do aborto na Câmara dos Deputados (RELATÓRIO ANUAL CDHM, 2013).

O presidente da CDHM abre a audiência comunicando que para que haja participação popular, ficaria disponível uma sala de bate papo no site "edemocracia", e assim, os deputados acessariam os links do bate papo pelos computadores da bancada. Além disso o mesmo afirma que 
"raramente uma audiência pública move tantos deputados quanto essa moveu", porém todos os deputados mencionados eram homens membros da bancada evangélica, de ideais conservadores a respeito do corpo da mulher.

O requerente, Deputado Henrique Afonso, apresenta na audiência um vídeo extraído do Youtube que apresenta falas fictícias de um nascituro, com o objetivo de sensibilizar os participantes.

Padre Paulo Ricardo de Azevedo Júnior pertence ao clero da Arquidiocese de Cuiabá (Mato Grosso - Brasil) e desde 2002, a Santa Sé o nomeou membro do Conselho Internacional de Catequese (Coincat), da Congregação para o Clero. É autor de diversos livros e apresenta semanalmente o programa "Oitavo Dia”, pela Rede Canção Nova de Televisão" (Fonte: canção nova). De acordo com o Blog do Reinaldo Azevedo, em 2012, a uma ala progressista da Igreja Católica de CuiabáMT, já pedia a cassação do Padre Paulo Ricardo de Azevedo Júnior.

A última atualização da Comissão de direitos humanos e minorias da câmara no seu site oficial declara que esta audiência pública fica arquivada. Em 2015 o Presidente comunicou o arquivamento de todos os requerimentos aprovados, rejeitados e não deliberados apresentados na legislatura passada.

Na imagem a seguir, que se trata de uma audiência para decidir os rumos que se dizem respeito ao corpo das mulheres, podemos ver que os presentes na audiência, principalmente com direito a fala, são homens, e homens de ideais conservadores. 


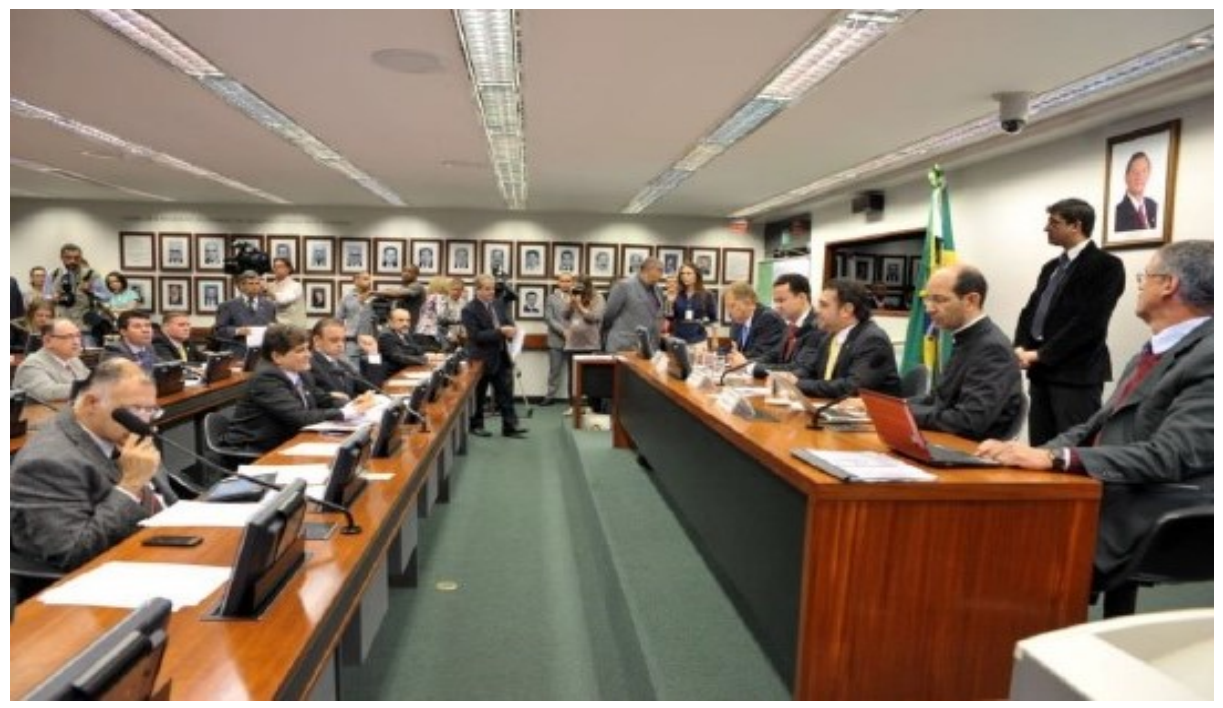

Audiência pública para discutir o aborto

As bases sociais institucionais e não institucionais que sustentaram a gestão do pastor Marco Feliciano na CDHM são contrárias as bandeiras feministas, as quais dizem respeito aos direitos da mulher sobre o próprio corpo, e isso efervesceu ainda mais o embate entre evangélicos e feministas na gestão do pastor na comissão, principalmente nesta audiência pública, a última realizada no ano gestado pelo pastor: a audiência pública ocorrida em 04/12/2013 para "Discutir o aborto", requerida pelo presidente Dep. Pastor Marco Feliciano;

Audiência pública para "Discutir o aborto", requerida pelo presidente da CDHM, Deputado Pastor Marco Feliciano. (RELATÓRIO ANUAL CDHM, 2013).

Depoente Convidado: HERMES RODRIGUES NERY Coordenador da Comissão Diocesana em Defesa da Vida da Diocese de Taubaté - SP. THEREZA DE LAMARE FRANCO NETTO - Diretora Substituta do Departamento de Ações Programáticas Estratégicas da Secretaria de Atenção à Saúde do Ministério da Saúde. 
Conforme a redação final da audiência, disponível no endereço eletrônico da Câmara dos Deputados, essa audiência pública também contou com a presença da Pastora Damares Alves6, Advogada, Educadora e Coordenadora do Projeto Educacional do Programa Proteger. pastora iniciou a sua participação com a seguinte fala:

eu não posso deixar de registrar os meus cumprimentos pela realização desta audiência sobre um tema tão polêmico. Esta Comissão já falou de direitos humanos de negros, de quilombolas, de índios, de doentes mentais, de contaminados pelo chumbo, de presos injustamente, da menina Duda, de erotização infantil. Se quiséssemos, talvez não conseguíssemos lembrar tudo o que esta Comissão fez este ano. E ela está fechando com chave de ouro, ao falar dos direitos daqueles que não nasceram, que estão por nascer. Parabéns, Deputado! Eles têm direito à vida (REDAÇÃO FINAL, CDHM, 2013).

Presença do Deputado Jair Bolsonaro com direito a fala

Presença do Deputado João Campos com direito a fala

Presença do Deputado Arolde de Oliveira com direito a fala

Presença da Deputada Antonia Lúcia com direito a fala

Presença da Deputada Liliam Sá com direito a fala

Na oposição Thereza de Lamare Franco Netto, mestre em Política Social pela Universidade de Brasília(2008) com experiência na área de Saúde Coletiva, com ênfase em Saúde Pública, com direito a fala.

Após apresentar as principais audiências públicas acontecidas na CDHM em 2013, vale destacar que segundo a regra de funcionamento das audiências públicas na comissão, quem convida os membros da sociedade civil é a própria diretoria da comissão e a CDHM é quase toda composta pelos deputados da bancada evangélicas. É a partir desse fato que continuo a reflexão a respeito dos atores sociais que

${ }^{6}$ Atual ministra da mulher, da família e dos direitos humanos. 
participaram com direito a fala dos principais eventos que dizem respeito aos rumos da democracia. Retomando a ABERS e seu olhar a respeito da "política de conflito" podemos citar

episodic, public, collective interaction among makers of claims and their objects when (a) at least one government is a claimant, an object of claims, or a party to the claims and (b) the claims would, if realized, affect the interests of at least one of the claimants (McADAM, Doug; TARROW, Sidney; TILLY, Charles, 2001, p05. Apud ABERS, 2011, p. 60)

Neste caso, a função de uma audiência pública deveria ser causar a uma interação conflituosa entre os atores, para que haja uma discussão "justa" a respeito dos assuntos referentes as decisões políticas, e dentro da comissão isso não acontece entre os atores que tem direito a fala nas tomadas de decisões, e isso fica claro na descrição de cada audiência pública.

\section{Os noticiários}

Trato aqui também dos noticiários, pois foram esses que mobilizaram os atores e atrizes sociais da sociedade civil a participarem das mobilizações a respeito das decisões de Feliciano. Por conta disto, também é de grande relevância investigar as notícias de diversos jornais e revistas que cobriram os conflitos e as disputas armadas pela chegada do deputado Pastor Marco Feliciano à presidência da comissão. Trato aqui de jornais e revistas de grande circulação e visibilidade nacional, a revista Veja e o jornal O Globo, os quais de algum modo atraem a atenção da sociedade civil para o determinado fato, consequentemente os mobilizando alguma forma, comprovando a efervescência da gestão de Feliciano.

A revista Veja, que no dia 7 de março de 2013, no Blog de Reinaldo Azevedo, noticiou a seguinte manchete: "Sob protestos, Marco Feliciano é eleito presidente da Comissão de Direitos Humanos e Minorias da Câmara". A publicação aborda que Marco Feliciano "fez 
declarações consideradas racistas e se manifestou contra a união civil entre homossexuais", devido a isso, manifestantes contrários as posições do deputado, na ocasião, ocuparam o plenário e tumultuaram a sessão. (VEJA, 2013)

Na mesma semana, o jornal O Globo, informou que "com 11 votos e um voto branco, a Comissão de Direitos Humanos e Minorias elegeu o polêmico pastor Marco Feliciano para o cargo de presidente". Esta notícia descreve as os acontecimentos, ocorridos na comissão, de forma mais detalhada, mostrando as discussões que "incendiaram" uma luta política entre atores contrários e atores favoráveis à figura polêmica do deputado. O Globo afirma que "cerca de 30 pessoas foram proibidas de participar da sessão e fizeram protesto do lado de fora". E além disso, também ficou registrado que "deputados bateram boca e trocaram farpas. Os que defendiam a eleição de Marco Feliciano acusavam os outros de discriminação por ele ser evangélico. Também enfatizaram que são contra a homofobia" (O GLOBO, 2013). Além disso, o site também declara que a primeira sessão do pastor na CDHM foi marcada por "tumultos", assim como na imagem a seguir extraída do jornal O Globo: 


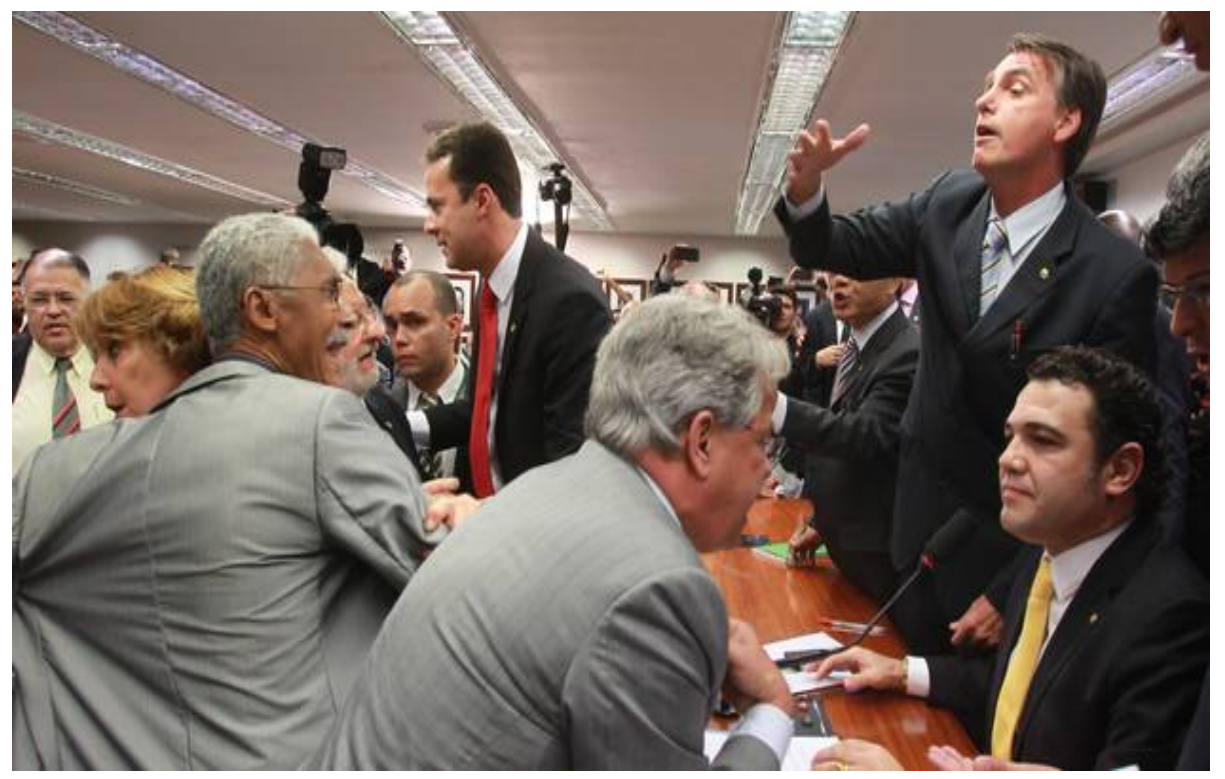

Além destes, o site Gospel Prime, jornal de alta visibilidade entre o público evangélico, noticiou que " mesmo enfrentando dura oposição e críticas de ativistas do Movimento LGBT, Feliciano foi eleito por unanimidade na manhã desta quinta-feira.". Contudo, o Gospel Prime já havia se mobilizado em apoio a indicação de Feliciano ao cargo na CDHM, pois dias antes de sua eleição, o jornal noticiou a seguinte manchete: "Marco Feliciano promove petição em seu site sobre presidência da CDHM", com o intuito de apoiar a petição a qual visava mostrar que havia quem defendesse sua indicação, disponibilizando aos seus leitores o link de acesso que apoiava o pastor.

Estes noticiários de grande circulação nacional, e muitos outros, os quais trouxeram à tona atores favoráveis e contrários a figura de Feliciano, respondem a proposta de explicar a força ativismo político evangélico e de seus opositores no ano de 2013. Por fim, 2013 foi um ano de embate a respeito da luta entre conservadores e feministas, levando estes as ruas e as portas da CDHM para se posicionarem contra ou a favor da gestão do pastor. 


\section{Conclusão}

Após pesquisar alguns dos documentos aqui descritos, os arquivos analisados, servem como base de uma pesquisa científica para identificar os atores e atrizes sociais e suas respectivas bandeiras conservadoras que se levantaram na defesa e à presença de Marco Feliciano na presidência da CMHM da Câmara e também mapeando as bases sociais dos deputados da Frente Parlamentar Evangélica, assim, comprova-se que a força do ativismo evangélico só tem aumentado devido as fortes bases sociais presentes na sociedade civil, bases que atravessam as fronteiras entre o estado e a sociedade, participando das decisões a respeito dos destinos do corpo da mulher.

\section{Referências}

ABERS, Rebecca; BULOW, Marisa Uon. Movimentos sociais na teoria e na prática: como estudar o ativismo através da fronteira entre estado e sociedade? Sociologias, Porto Alegre, v. 13, n. 28, p. 52-84, set./dez. 2011.

Apoio a Petição de Marco Feliciano. Disponível em: https:/ / www.gospelprime.com.br/peticao-marco-felicianocomissao-direitoshumanos/. Acesso em: 24 ago. 2020.

Atualização dos deputados da Frente Parlamentar Evangélica, Disponível em: https://www.camara.leg.br/internet/deputado/frenteDetalhe.asp?i d=54010. Acesso em: 25 ago. 2020.

BIROLI, F. Reação conservadora, democracia e conhecimento. Revista de Antropologia (USP), v. 61, n. 1, 83-94, 2018.

CASSOTTA, Priscilla Leine. Uma análise do comportamento dos deputados evangélicos no legislativo brasileiro. E-legis, Brasília, n. 20, p. 75-101, maio/ago. 2016.

CELLARD, A. A análise documental. In: POUPART, J. et al. (Org.). A pesquisa qualitativa: enfoques epistemológicos e metodológicos. Petrópolis: Vozes, 2008. 
CÉSAR, J. B. M. A audiência pública como instrumento de efetivação dos direitos sociais. Revista do Mestrado em Direito da Universidade Católica de Brasília: Escola de Direito, Brasília, v. 5, n. 2, p. 356-384, jul. 2011.

DAGNINO, Evelina. OLVERA, Alberto J., PANFICHI, Aldo. Para uma outra leitura da disputa pela construção democrática na América Latina. In: A Disputa pela Construção Democrática na América Latina. São Paulo: Paz e Terra, 2006. p. 13-91.

FRESTON, Paul Charles. Protestantes e política no Brasil: da Constituinte ao Impeachment. Tese (Doutorado em Sociologia) - Universidade Estadual de Campinas, Campinas, SP, 1993.

Funcionamento das audiências públicas. Disponível em: https:/ / www2.camara.leg.br/atividadelegislativa/comissoes/comissoes-permanentes/cft/audienciaspublicas/Normas\%20Regimentais. Acesso em: 24 ago. 2020.

GONÇALVES, R. B. A atuação de Marco Feliciano na comissão de Direitos Humanos e Minorias (CDHM). Mandrágora, v. 23, p. 205-245, 2017.

Jornal O Globo. Disponível em: https:/ / oglobo.globo.com/brasil/ pastor-marco-feliciano-assumecomissao-de-direitos-humanos-7767447. Acesso em: 24 ago. 2020.

Jornal Globo. Disponível em: https:/ /oglobo.globo.com/brasil/ primeira-sessao-da-comissao-dedireitos-humanos-marcada-por-tumulto-7828150. Acesso em: 24 ago. 2020.

MARIANO, Ricardo. Deus é voto. Revista de História da Biblioteca Nacional, Rio de Janeiro, ano 8, n. 87, 2012.

Notícia Gospel Prime. Disponível em: https:/ / www.gospelprime.com.br/marco-feliciano-eleito-comissaodireitos-humanos/. Acesso em: 24 ago. 2020.

PINHEIRO, L. P. Análise Representativa a respeito da Frente Parlamentar Evangélica de 1994 a 2014, Juiz de Fora, 2017.

Redação final da Audiência Pública para discutir o aborto. Disponível em:

https://www2.camara.leg.br/atividade- 
legislativa/comissoes/comissoes-

permanentes/cdhm/documentos/notas-taquigraficas/4-12-2013-

reuniao-ordinaria-e-audiencia-publica/view. Acesso em: 25 ago. 2020

Relatório Anual da Comissão dos Direitos Humanos e Minorias da Câmara. Disponível em: http://www2.camara.leg.br/atividadelegislativa/comissoes/comissoes-

permanentes/cdhm/documentos/relatorios-de-atividades. Acesso em: 25 ago. 2020.

Revista

Veja.

Disponível

em:

https:/ / veja.abril.com.br/blog/reinaldo/sob-protestos-marcofeliciano-e-eleito-presidente-da-comissao-de-direitos-humanos-dacamara/. Acesso em: 24 ago. 2020.

ROMAO, W. M. Nas Franjas da Sociedade Política: Estudo sobre o orçamento participativo. Tese de Doutorado. USP. São Paulo, 2010. 